\title{
Experimental study of shear-key equipped pile to grout connection under cyclic loading
}

\author{
Matias Silva ${ }^{1}$, Orianne Jenck ${ }^{2,}$, Fabrice Emeriault ${ }^{2}$, and Jean Benoit Toni ${ }^{2}$ \\ ${ }^{1}$ Universidad Técnica Federico Santa María, Valparaíso, Chile \\ ${ }^{2}$ Univ. Grenoble Alpes, CNRS, Grenoble INP, 38000 Grenoble, France
}

\begin{abstract}
A technical solution for tidal turbine foundation in granite seabed consists of grouted steel piles. The piles would be subjected to cyclic loading due to the severe service conditions. The mechanical behaviour at the interface between the pile and the surrounding media is one of the key points that determine the bearing capacity of the foundation system. Experimental research work has been carried out in the laboratory to study the grouted pile-to-rock connection (GPRC) and focused more precisely on the pile to grout connection when the pile is equipped with shear-keys that enhance the interface capacity. Monotonic and cyclic shear tests were performed using a specific direct shear test device (BCR3D), allowing application of sample confining conditions close to the in-situ conditions, namely constant normal stiffness conditions. Cyclic tests - either under one way or twoway shear loading application - were performed on several samples, under both constant volume and various constant stiffness boundary conditions. This study has shown that the strength of the interface is highly dependent on the combination of mean load, cyclic amplitudes and number of cycles applied to the interface. Cyclic failure was observed with less than 30 cycles for two-way and one-way cyclic loading.
\end{abstract}

\section{Introduction}

Cylindrical shaped grouted connections have a positive track record of usage, tracing back 1970s in jacket structures in the oil and gas industry. At that time, the design of grouted-connection with shear keys was not explicitly regulated in the old American Petroleum Institute (API) or UK Health \& Safety Executive (HSE) guidance. However, its usage was not ruled out. Comprehensive studies of grouted-connection with shear keys started towards the end of the seventies, notably with the experiments conducted by [1]. It was then accepted that the total grouted length could be reduced by the inclusion of shear keys in the connection, leading to enhanced popularity of shear-keyed connection.

Further experimental research continued based mainly on small model tests at a laboratory scale [2]. In 2009, Det Norske Veritas (DNV) launched an extensive experimental campaign as Joint Industrial Research Program (JIP) to revise the recommended design practice and to investigate a design option of grouted connection with shear keys. Tests were carried out on large diameter samples, this time, with an emphasis on possible scale effects when designing offshore grouted connections based on laboratory models [3].

Concerning the behaviour of the shear-keyed connection when subjected to cyclic loading, most of the available data in the literature refers to small laboratory samples applying symmetric loadings concerning the ultimate strength. [4], were among the first to conduct interface-cyclic loading tests on grouted pile-sleeve samples. Their results indicate a limit value for $40 \%$ of the ultimate interface strength below which no failure occurs at less than 107 cycles and where possibly failures do not occur at all. On the other hand, [5], comparing grouted interfaces behaviour on dry and wet samples, argued that no failure would occur if fatigue does not exceed $50 \%$ of the ultimate axial load capacity of the small-scaled grouted joints. These results reveal a high impact on the number of endurable cycles under fatigue loading when tested submerged in water where a possible phenomenon of hydro lubrication in the contact interface may appear, leading to increasing local stresses and, therefore, a faster degradation of the grout. The applied test frequency might significantly influence these effects. Similar conclusions were reached by other authors [3], when analysing existing data with results of a JIP project, suggesting to reduce the level of the design stress-cycle (S-N) curve by a factor 0.8 compared to the guidelines for concrete structures using the DNV design guidelines.

Tests conducted by [6], were also performed taking into account the effect of early age cyclic loading (cyclic loading during curing time) and the effect of the shear keys geometry. They observed that large and densely spaced shear keys lead to reduced shear strength while too closely spaced shear keys may cause early age cycling to produce a very significant reduction of strength.

* Corresponding author: orianne.jenck@3sr-grenoble.fr 
The fatigue design of offshore grouted connections requires the analysis of both the interface response to the cyclic loadings and its loading history. The variety of fatigue calculation methods shows that there is no single approach being used [7], the main reasons being practical and contractual compulsions in the offshore wind industry. Several authors $[8,9]$, have recently presented general methodologies for offshore pile design in sands and chalk respectively, which include the effect of axial cyclic loads on the foundation response. Both methodologies present the analyses and characterisation of sea storms and how to represent their effect on the piled foundation and could be generalised for the design of grouted connections.

This article presents the results of an experimental research work carried out to study the interface behaviour of grouted pile-to-rock connections (GPRC, Figure 1), where a pile is embedded in the seabed with grout filling the gap between the steel pile and the seabed rock.

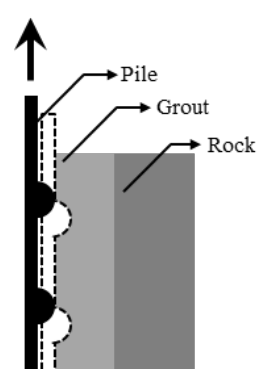

Fig. 1. Scheme of a GPRC grouted connection

\section{Experimental campaign}

\subsection{Shearing device}

The grout-shear keys interface behaviour was studied using a 3-D servo-controlled direct shear machine named "BCR3D" (for its French acronym Boîte de Cisaillement pour joints Rocheux 3D). This machine was conceived and fabricated in the Laboratory 3SR in Grenoble, France, [10], and it has been used in the past to characterise rock fractures and rock/concrete interfaces [11].

A general view of this apparatus is shown in Figure 2. This apparatus allows for loading in three different directions referred to as $\mathrm{X}, \mathrm{Y}$ and $\mathrm{Z}$ ( $\mathrm{Z}$ being the vertical loading; while $\mathrm{X}$ and $\mathrm{Y}$ the transverse loading directions) by using five independent hydraulic rams. The $\mathrm{X}$ and $\mathrm{Y}$ loading axis is composed of two independent jacks connected to two consecutive $1 / 36$ reduction gears. Their combined use, in addition to the vertical jack which imposes the confining normal stress to the sample, allows for the development of fully three-dimensional solicitations to the sample. Additional features include the possibilities of injecting fluid to the sample and performing dynamic loadings.

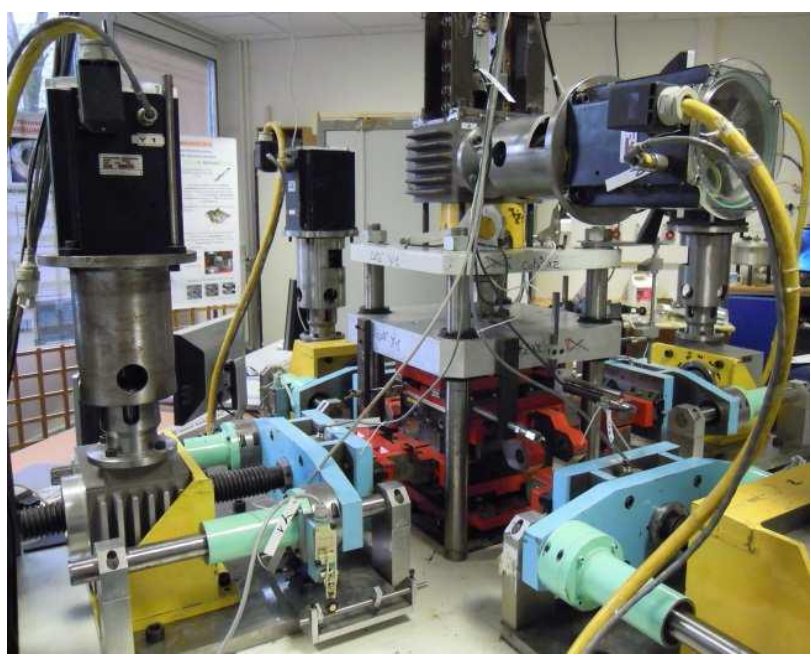

Fig. 2. General view of the BCR3D apparatus at the Laboratory 3SR in Grenoble, France

The behaviour of a steel-grout interface was studied at the local scale of the interface. Additional tests were carried out on cement grout samples to obtain their mechanical properties. Following simplifications and assumptions were defined for the correct assessment the interface behaviour during interface cyclic shearing:

- Offshore grout mixtures cannot be used in smallscale laboratory models due to their high mechanical resistance. The full-scale model would be required when using this type of grout. Therefore, the cement-based grout should present mechanical resistances in the measurement range of laboratory equipment.

- The size of shear keys normally used in offshore structures cannot be used in small-scale interface tests due to geometrical restrictions in the apparatus for grout-steel interface testing. Smaller shear keys were defined in compliance with standards.

- The cyclic response of grouted connections requires a high number of parameters concerning the characterisation of cyclic solicitations, e.g. number of cycles, level of loading, the sequence of loading, cumulative damage effect of cyclic loading. The number of cycles and loading levels were restricted to the apparatus performance limits.

The grout-pile interface samples were prepared on specially adapted steel boxes for the BCR3D apparatus, as observed in Figure 3. Each one of these boxes consists of two independent parts (bottom and top boxes), with a spacing of $15 \mathrm{~mm}$ between them to simulate the interface between grout and shear keys. The metal plates with the shear keys that simulate the surface of an offshore steel pile are carefully placed inside before filling with fresh grout. It is expected for the upper edge of the shear keys to coincide with the central axis of the shearing plane.

Each steel plate was prepared with between 2 and 5 shear keys as stated by API's design recommendations on using a Shear key ratio (shear key height over spacing) of $\mathrm{h} / \mathrm{s} \leq 0.10$, and a Shear key shape factor (shear key height over width) of $1.5 \leq \mathrm{w} / \mathrm{h} \leq 3$. 


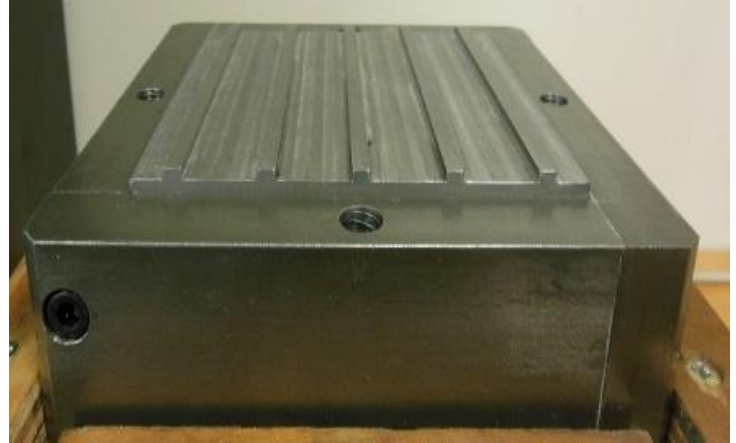

Fig. 3. Example of BCR3D bottom box with a solid steel plate with shear keys

\subsection{Sample preparation}

The cement grout used by the offshore industry for structural pile-sleeve connections is composed mainly of a water-cement mix with a ratio of up to 0.36 and the presence of additives or fibres to modify their properties. These mixtures lead to unconfined compressive strength ranging from 70 to $120 \mathrm{MPa}$ [12]. The research presented here considered two types of cement-based grout mixes: i) Portland cement CEM I 52.5R with water/cement ratio, $\mathrm{w} / \mathrm{c}$, of 0.4 with no additive or granular material (hereafter referred as DC samples); and ii) industrial hydraulic grouting mortar (SikaGrout-217 produced by Sika), composed of silica sand with grain size ranging up to 1.6 $\mathrm{mm}$, Portland cement and additives (hereafter referred as SG samples). Unlike Portland cement samples, a w/c ratio of 0.15 was used in the SG mixture, following the indications provided by the manufacturer. Unconfined Compressive Tests (UCS) conducted after 28 days of curing time reached strengths in the range of 66 to 70 MPa.

\subsection{Imposed boundary conditions}

One of the difficulties of performing small laboratory tests is how to correctly represent real field conditions. To overcome this problem, the BCR3D apparatus is configured to apply a Constant Normal Stiffness (CNS) boundary condition to the sample which intends to correctly represent the interface behaviour. The interface stiffness, $\mathrm{k}_{\text {normal }}$, is maintained constant by adjusting the normal stress with respect to the normal displacement of the interface.

This boundary condition is intermediary between the Constant Volume boundary condition (CV), which represents infinite normal stiffness, and the Constant Normal Load (CNL), where no lateral stiffness is imposed allowing for larger deformations and softer interface responses. Figure 4 shows an illustration of these three boundary conditions.

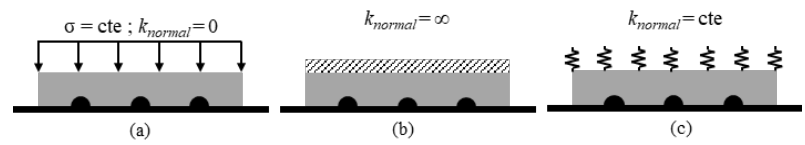

Fig. 4: Three types of interface boundary conditions: (a) constant normal load (CNL); (b) constant volume (CV); (c) constant normal stiffness (CNS).
As described by [13], during shearing, the variation in normal stresses acting along the interface, $\Delta \sigma$, and the variation in the interface dilation, $\Delta \mathrm{u}$, will be related (from elastic expanding cylinder theory) to the properties of the confining material and to the pile radius by the following equation:

$$
\Delta \sigma_{n}=\frac{E}{1+\nu} \cdot \frac{\Delta u}{r}
$$

where $r$ is the original pile radius, E and $v$ the Young's modulus and Poisson ratio of the confining material respectively, e.g. a rock mass in the case of socketed piles. Equation (1) can be rearranged, if $\Delta \mathrm{u}$ is small compared to the pile radius $r$, and since the elastic properties of the confining material are effectively constant for small changes in $\Delta r$, to:

$$
\frac{\Delta \sigma_{n}}{\Delta u}=\frac{E}{1+\nu} \cdot \frac{1}{r}=K
$$

where $\mathrm{K}$ is a constant and represents the Constant Normal Stiffness applied to the interface.

[14] based on pressumeters tests in sands proposed a slightly different formulation for the interface's stiffness, $\mathrm{K}$, which considers a factor of 2 when multiplying the elastic modulus of the material.

The concept of an interface stiffness related the pile diameter, and the grout properties are somehow embedded in the stiffness parameter $\mathrm{K}$, that later became part of the ISO design code.

For the tests herein presented, GPRC connections were assumed based on offshore monopiles diameters, $r=$ $1,150 \mathrm{~mm}$, and a competent granite rock mass, Young modulus of $50 \mathrm{GPa}$, the values of stiffness will then range from 20,000 to $40,000 \mathrm{kPa} / \mathrm{mm}$ respectively based on the work by $[13,14]$.

\section{Experimental programme}

Series of cyclic loading tests were performed during this research study to evaluate the response of a model grouted interface to cyclic loading.

Cyclic loading was applied using a stress control system where predefined shear stresses were set for each cyclic test. Cyclic failure was defined as the state (related to a specific number of cycles) where these limits could not be attained leading to a progressive uncontrollable increment in shear displacement. A maximum shear displacement of $12 \mathrm{~mm}$ was allowed before stopping the test, corresponding to approximately $10 \%$ of the steel plate length.

A maximum of 1,500 cycles was performed during the experimental campaign. Only four tests reached failure, and the remaining tests showed signs that failure could be obtained if cyclic loading continues. Unlike static failure, where a sudden variation in stresses and/or displacement is observed due to the mechanical breakage of the grout, cyclic failure shows a softening response represented by the accumulation of permanent shear displacement. Examples of failure response are given in the following sections. 
The mean cyclic load, $\mathrm{Q}_{\text {mean, }}$ and half-amplitude load of the cycles, $\mathrm{Q}_{\text {cyclic }}$, have been by defined by Equations (3) and (4) with respect to the maximal and minimal loads during cyclic loading:

$$
\begin{aligned}
Q_{\text {mean }} & =\frac{Q_{\max }+Q_{\min }}{2} \\
Q_{\text {cyclic }} & =\frac{Q_{\max }-Q_{\min }}{2}
\end{aligned}
$$

Series of one way (OW) and two ways (TW) cyclic loading tests were carried out during the experimental campaign. The concept of one-way cyclic loading tests refers commonly to cyclic loads where the average load and the cyclic amplitude stay within a region without stress reversal, i.e. the shear stresses will be purely tensile or purely compressive. On the contrary, two-way cycles will be characterised by a stress reversal where the interface is subjected to both compressive and tensile stresses during each cycle.

The following Table 1 summarises the main parameters of the experimental campaign. All the tests were performed on samples with four shear keys $(\mathrm{h} / \mathrm{s}$ ratio of 0.078). Vertical boundary conditions of Constant Volume (i.e. infinite stiffness) and constant normal stiffness of 10,000 and $40,000 \mathrm{kPa} / \mathrm{mm}$ samples were imposed.

\begin{tabular}{|c|c|c|c|c|}
\hline Test ID & $\begin{array}{c}C N S \\
(\mathrm{kPa} / \mathrm{mm})\end{array}$ & $\begin{array}{c}\mathbf{Q}_{\text {mean } /} \\
\mathbf{Q}_{\text {s }}\end{array}$ & $\begin{array}{c}\mathbf{Q}_{\text {eyclic/ }} \\
\mathbf{Q}_{\mathbf{s}}\end{array}$ & $\begin{array}{c}\text { \# of } \\
\text { cycles/Nf }\end{array}$ \\
\hline $\mathrm{OW} 1^{\mathrm{DC}}$ & \multirow{6}{*}{$\infty *$} & 0.254 & 0.183 & 50 \\
\hline $\mathrm{OW} 2^{\mathrm{DC}}$ & & 0.329 & 0.257 & 35 \\
\hline OW3 DC & & 0.408 & 0.336 & 45 \\
\hline OW4 $\mathrm{DC}$ & & 0.487 & 0.415 & 6 \\
\hline TW1 ${ }^{\mathrm{DC}}$ & & 0.000 & 0.270 & 30 \\
\hline TW2 $2^{\mathrm{DC}}$ & & 0.014 & 0.443 & 15 \\
\hline $\mathrm{OW5}^{\mathrm{SG}}$ & \multirow{3}{*}{10,000} & 0.514 & 0.248 & 1,500 \\
\hline OW6 ${ }^{\mathrm{SG}}$ & & 0.509 & 0.446 & 650 \\
\hline OW7 SG & & 0.213 & 0.115 & 50 \\
\hline TW3 ${ }^{\text {SG }}$ & \multirow{5}{*}{40,000} & 0.007 & 0.248 & $21 *$ \\
\hline OW8 ${ }^{\text {SG }}$ & & 0.288 & 0.273 & 468 \\
\hline TW4 ${ }^{\mathrm{DC}}$ & & 0.004 & 0.319 & $111^{*}$ \\
\hline OW9 SG & & 0.282 & 0.282 & $18^{*}$ \\
\hline TW5 ${ }^{\text {SG }}$ & & 0.000 & 0.130 & $905 *$ \\
\hline
\end{tabular}

Table 1. Experimental programme

${ }^{\mathrm{DC}}$ Portland cement samples; ${ }^{\mathrm{SG}}$ Sika Grout samples; *cyclic failure

\section{Results}

The following Figure 5 presents a summary of the results with the different cyclic tests conducted according to Table 1 above in the form of a stability chart [15]. On these charts, the $\mathrm{x}$-axis and $\mathrm{y}$-axis represent the ratio between the mean cyclic load $\mathrm{Q}_{\text {mean }}$ and the half cyclic load $\mathrm{Q}_{\text {cyclic }}$ respectively and the tensile (or also compressive) static capacity $\mathrm{Q}_{\mathrm{s}}$.

The different arrows in Figure 5 indicate the sequence of consecutive loading followed for a sample. The number next to each point indicates either the number of applied cycles (e.g. $>1,500)$ or the number of cycles at failure, $\mathrm{N}_{\mathrm{f}}$.

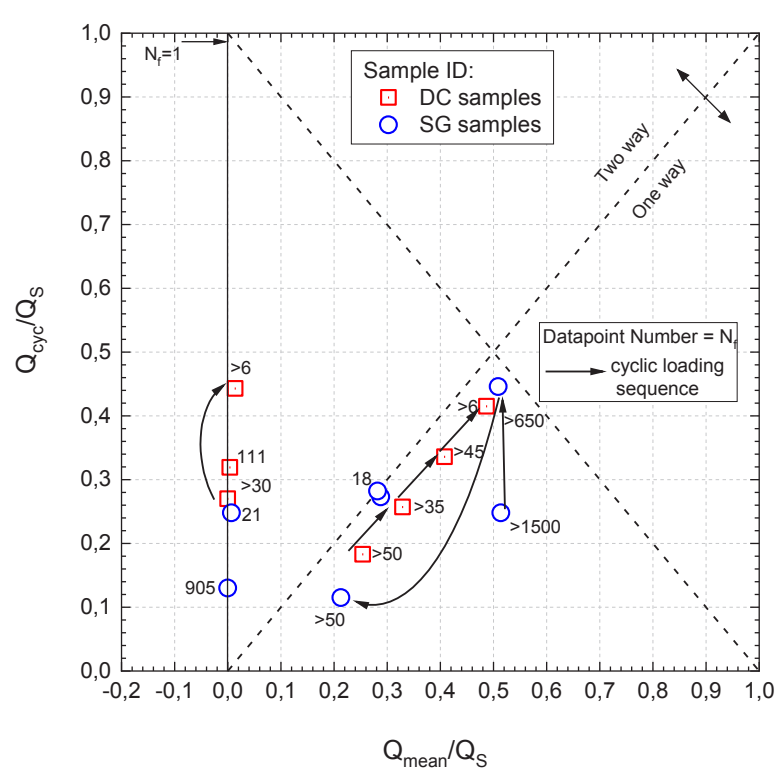

Fig. 5. Summary of the experimental campaign in the form of a stability chart

Except for test OW9, all tests in the One-way region did not show signs of failure, and probably cyclic loading could have continued for several thousands of cycles. Low-level OW cycles, lower than $25-30 \%$ of Qs, could show stable responses that would allow performing thousands of cycles before signs of potential failure. Increasing the cyclic amplitude would progressively move to less stable behaviour and to the appearance of a more unstable behaviour where sudden failure may be observed. On the contrary, higher loading levels in the two-way region led to failure between 20 and 900 cycles.

\subsection{One Way cyclic loading tests}

For practical reasons, OW cyclic loads are mainly referred to tension loads in piled foundation due to the difficulties of correctly assessing the base resistance of a pile. In our case given the geometry of the BCR3D apparatus, we do not refer to tensile or compressive loads at the interface since the direction of loading is mainly referential.

Figure 6 presents an example of the imposed loading during tests OW1-OW3 which were conducted consecutively. In this case, the minimum load remains constant and both the cyclic amplitude $\mathrm{Q}_{\text {cyclic, }}$ and cyclic average load, $Q_{\text {mean }}$, increased progressively during cyclic loading, given that no apparent failure took place during previous tests.

The increase in load is accompanied by an increase in permanent shearing displacement, without any sign of potential failure. The amplitude of shearing displacement and the permanent cumulative displacement increase when increasing loading levels. A similar trend for the shearing displacement evolution is observed during test OW6, Figure 7, loaded to higher values than those in Figure 6. The initial accumulation of shearing displacements tends to stabilise after ten cycles suggesting cyclic loading could continue in a stable regime without changes beyond 50 cycles. 


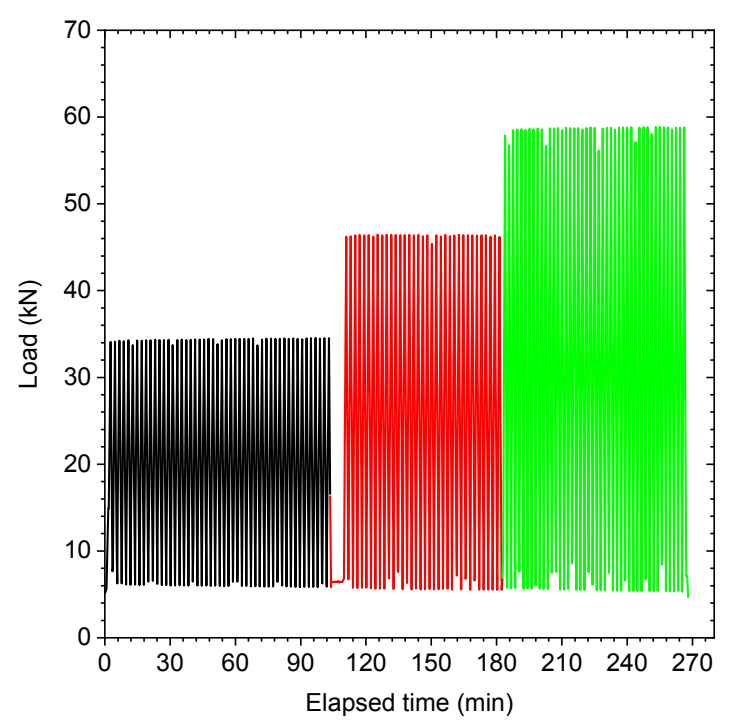

Fig. 6. Example of loading sequence during tests OW1-3 performed under Constant Volume boundary condition

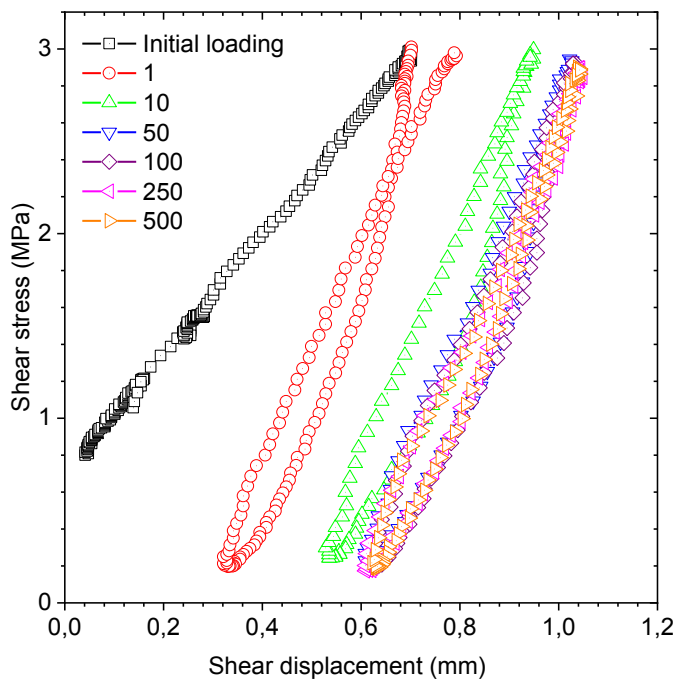

Fig. 7. Evolution of shear stress versus shear displacement during test $\mathrm{OW} 6$ performed under $\mathrm{CNS}=10,000 \mathrm{kPa} / \mathrm{mm}$

Additional tests performed for more than 1,500 cycles with similar mean load at higher cyclic amplitude cyclic showed similar behaviour without signs of failure. If we now look at test OW9, Figure 8, the only one-way cyclic test that reached failure, it can be noticed that the instability in the cyclic response appeared suddenly leading to a rupture and the displacement required to mobilise the imposed shear stress becomes too important. This behaviour can be understood by looking at the evolution of interface stress path during cyclic loading. Figure 8 shows how the stress path tends to move to the right in the plane closer to the residual state. This response is representative of unstable behaviour where failure takes places rapidly. The equivalent interface friction angle tends to reduce from $60^{\circ}$ to $50^{\circ}$ when increasing permanent shear displacement.

On the contrary, cycles at lower levels of amplitude tend to stabilise after a few cycles without variations in the interface behaviour. In both cases, cyclic loading shows a constant repeated cyclic loop (or hysteresis).

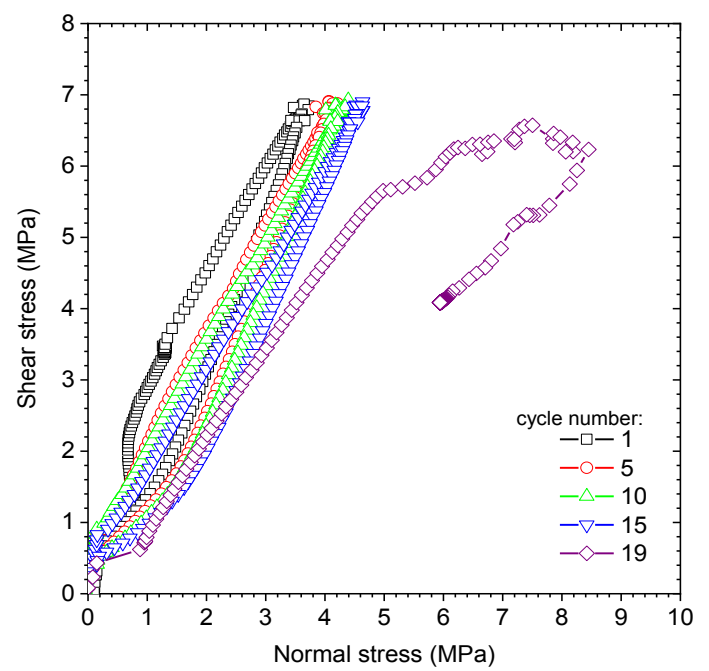

Fig. 8. Interface stress path during tests OW9. SG sample. CNS: $40,000 \mathrm{kPa} / \mathrm{mm}$

\subsection{Two Way cyclic loading tests}

Two-way cyclic loading tests imply a stress reversal process normally from tensile to compressive shear stress (e.g. push and pull sequence of the pile).

Table 1 showed that an important number of the TW cyclic tests reached failure at some cycles lower than equivalent $\mathrm{OW}$ tests with a similar cyclic amplitude. The process of stress reversal may lead to a phenomenon of interface progressive damage as what is observed during static interface test, where resistances are highly diminished after initial loading.

Figure 9 presents examples of the stress path from test TW3. In this case, cyclic failure was reached after 21 cycles. As for the mechanisms observed during OW test, see Figure 8, during a cyclic failure the interface stress path moves to a residual state rapidly once failure is attained. Two-way cyclic loading tests are characterised by the development of "butterfly wing" stress paths as result of the inversion in the loading direction. For Figure 9 , symmetric TW tests were observed. The mean load was imposed to be equal to zero, and the same cyclic amplitude is imposed in tension and compression. As cyclic loading progresses, these "butterfly wings" tend to decrease, the characteristic interface friction angle simultaneously moving to values close to a residual state. These conclusions seem consistent with the representation of the interface behaviour by [16], who represented the interface behaviour during cyclic loading as a progressive and cumulative failure compared to the monotonic failure.

This response is also observed when looking at the evolution of shear displacement. Failure appears suddenly with an accumulation of permanent displacement that cannot be compensated with the change in the loading direction. These results seem to agree with those of [4], who concluded that no cyclic failure would occur for twoway cyclic loading tests with amplitudes lower than 0.4 times the monotonic resistance, $\mathrm{Q}_{\mathrm{s}}$. 


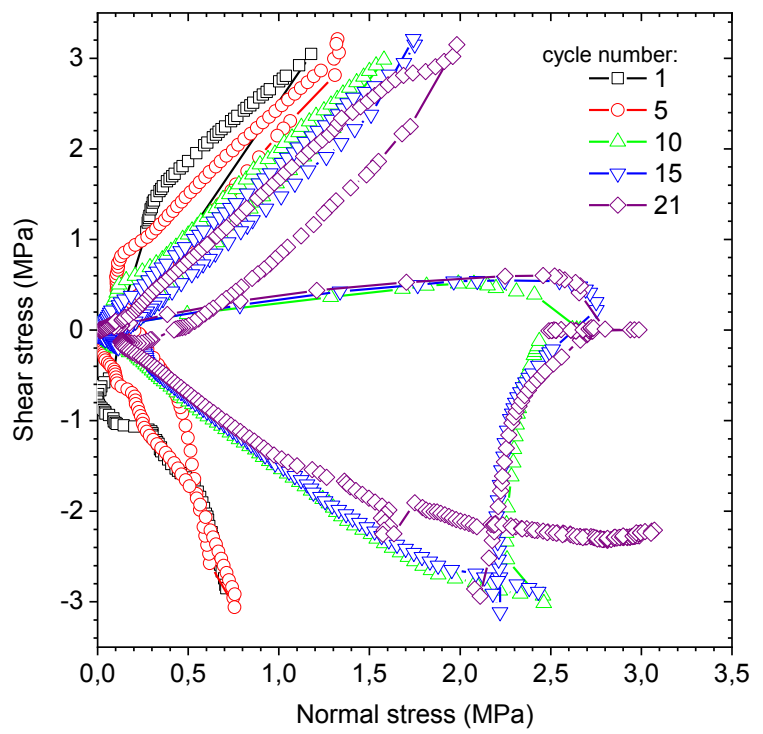

Fig. 9. Evolution of interface stress-path during test TW3, CNS: $40,000 \mathrm{kPa} / \mathrm{mm}$

\section{Conclusions}

The experimental campaign presented here analysed the response of grouted connections to cyclic interface shearing and evaluated the effect of several parameters in the final interface resistance.

The cyclic response of the interface is related to the magnitude regarding shear loading and extension of the imposed cycles. One Way cyclic loading tests under relatively low cyclic amplitude showed stable behaviour up to 1,500 cycles (maximum amount of cycles applied during cyclic loading). No cyclic failure was observed under several combinations of loading.

On the contrary, in the case of two-way cyclic loading tests where stress reversal is applied to the interface, failure may occur with a small number of applied cycles (in some cases below 50 cycles).

The authors acknowledge the French Environment \& Energy Management Agency, ADEME, for funding this research through the Pile\&Tide project.

\section{References}

1 C.J. Billington, G.H.G. Lewis, The strength of large diameter grouted connections, Proceedings of offshore technology conference, pp. 291-301 (1978).

2 P. Dallyn, A. El-Hamalawi, A. Palmeri, R. Knight, Experimental testing of grouted connections for offshore substructures: A critical review. Structures, 3, pp. 90-108 (2015).

3 I. Lotsberg, A. Serednicki, Behaviour of grouted connections of monopile structures at ultimate static and cyclic limit states, The Structural Engineer, February, pp. 51-57 (2013).

4 C.J. Billington, I.E. Tebbett, Fatigue strength of grouted tubular steel connections for offshore structures, Int. Assoc. Bridg. Struct. Eng., pp. 625-
632 (1982).

5 P. Schaumann, A. Raba, A. Bechtel, Impact of Contact Interface Conditions on the Axial Load Bearing Capacity of Grouted Connections, Proceedings of EWEA (2013).

6 Det Norske Veritas Industry AS, Report No: 943243, Factors of Safety for Grouted Connection Phase II the Impact of Cyclic Load on Connections with High H/S Values (1994).

7 J. Van Der Tempel, Design of support structures for offshore wind turbines, Doctoral dissertation, TU Delft, Delft University of Technology (2006).

8 A. Merritt, F. Schroeder, R. Jardine, B. Stuyts, D. Cathie, W. Cleverly, Development of pile design methodology for an offshore wind farm in the North Sea, in Offshore Site Investigation and Geotechnics: Integrated Technologies-Present and Future (2012).

9 J. Dührkop, A.H., Augustesen, P. Barbosa, Cyclic pile load tests combined with laboratory results to design offshore wind turbine foundations in chalk, Proc. Conf. Frontiers in Offshore Geotechnics III (ISFOG), pp. 533-538 (2015).

10 M. Boulon, A 3-d direct shear device for testing the mechanical behaviour and the hydraulic conductivity of rock joints, Proc., MJFR-2 Conference, pp. 407413 (1995)

11 O. Buzzi, Hydromécanique du contact entre géomatériaux: expérimentation et modélisation. Application au stockage de déchets nucléaires, Université Joseph-Fourier-Grenoble I (2004).

12 P.L.J. Domone (Ed.), D.S.A. Jefferis (Ed.), Structural Grouts. London: CRC Press, $1^{\text {st }}$ Edition (1993).

13 I.W. Johnston, T.S.K. Lam, A.F. Williams, Constant normal stiffness direct shear testing for socketed pile design in weak rock, Geotechnique, 37, 1, pp. 83-89 (1987).

14 M. Boulon, P. Foray, Physical and numerical simulation of lateral shaft friction along offshore piles in sand. Proceedings of the 3rd International Conference on Numerical methods in Offshore piling, pp. 127-147 (1986).

15 H.G. Poulos, Cyclic Stability Diagram for Axially Loaded Piles, Journal of Geotechnical Engineering, 114, 8, pp. 877-895 (1988).

16 D.S. Anders, Betontechnologische Einflüsse auf das Tragverhalten von Grouted Joints genehmigte Dissertation (2007). 